\title{
Lymphangioleiomyomatosis presenting in a postmenopausal woman
}

\author{
WILLIAM SINCLAIR, JL WRIGHT, ANDREW CHURG \\ From the Department of Pathology, University of British Columbia, Vancouver, British Columbia, Canada
}

Lymphangioleiomyomatosis is a rare pulmonary disorder characterised by proliferation of smooth muscle diffusely throughout the lung parenchyma. Most patients present during their reproductive years, and survival is generally less than 10 years. We report a case in a postmenopausal woman that was associated with long survival.

\section{Case report}

A 72 year old caucasian woman was admitted to hospital because of progressive respiratory failure. She had never been a smoker, and had worked as an audit supervisor for a department store. Her previous medical history included two severe episodes of pneumonia about 20 years before admission, and a hysterectomy at the age of 55. For the previous 10 years she had been investigated and treated for obstructive lung disease presumed to be due to late onset asthma. Seven years before admission she had shown appreciable gas trapping, with a total lung capacity of $110 \%$ predicted and a residual volume of $184 \%$ predicted; diffusing capacity was $33 \%$ predicted. At that time her $\mathrm{FEV}_{1}$ was $0.5 \mathrm{l}$, forced vital capacity (FVC) $1.4 \mathrm{l}$, and forced expiratory flow $\left(\mathrm{FEF}_{25-75}\right) 0.31$ ( $14 \%$ predicted).

During this admission her arterial oxygen tension $\left(\mathrm{PaO}_{2}\right)$

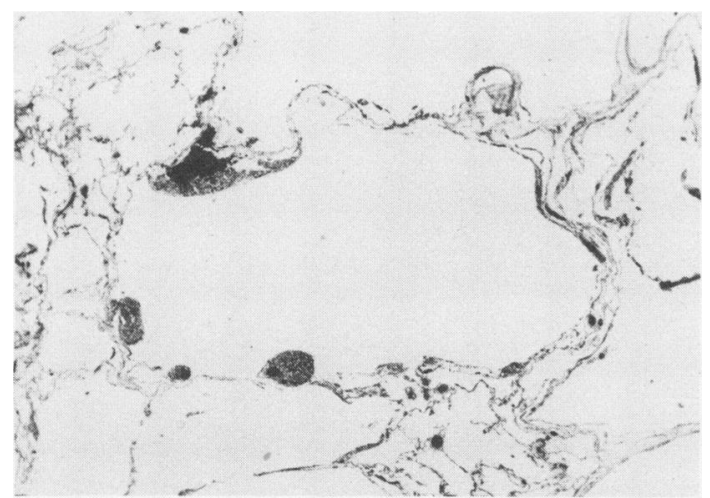

Fig 1 Typical area showing the very mild degree of muscle proliferation seen in the lungs of this patient. There are small irregular bundles of smooth muscle present in the walls of cyst like structures. (Masson's trichrome, $\times 12$.)

Address for reprint requests: Dr JL Wright, Department of Laboratory Medicine, University of British Columbia Health Sciences Hospital, 2211 Wesbrook Mall, Vancouver, British Columbia V6T 2B5, Canada.

Accepted 26 October 1984 was $66 \mathrm{~mm} \mathrm{Hg}(8.8 \mathrm{kPa})$, carbon dioxide tension $\left(\mathrm{PaCO}_{2}\right)$ $56 \mathrm{~mm} \mathrm{Hg}(7.5 \mathrm{kPa})$, and $\mathrm{pH} \mathrm{7.38}$. Routine spirometry showed her $\mathrm{FEV}_{1}$ to be 0.31 ( $21 \%$ predicted) and FVC 0.71 ( $33 \%$ predicted). These results were considered to be consistent with chronic airways obstruction. A chest radiograph showed hyperinflated lungs with a fine diffuse bilateral reticular pattern. The serum $\alpha_{1}$ antitrypsin concentration was 410 (normal $220-380$ ) $\mathrm{mg} / 100 \mathrm{ml}$. She was treated with bronchodilators and oxygen, but she died of increasing respiratory failure with associated cor pulmonale.

At necropsy, the lung had a multicystic appearance with the characteristic microscopic findings of lymphangioleiomyomatosis (figs 1 and 2). Similar nodules of irregular muscular proliferations were present in the hilar lymph nodes, and in a soft brown nodule present in a subdiaphragmatic position. The left kidney as well as both adrenals contained microscopic foci of smooth muscle arranged in irregular bundles with adjacent cystic spaces. The considerable right ventricular hypertrophy, with a left to right ventricular weight ratio of $1.2: 1$ (normal $2.3: 1$ ), correlated well with the clinical impression of cor pulmonale.

\section{Discussion}

Lymphangioleiomyomatosis is an uncommon pulmonary condition. The aetiology and pathogenesis are obscure; the disease progresses, leading to death usually within 10 years.' It generally presents during the child bearing years, and this, together with exacerbations with menses ${ }^{2}$ and during pregnancy, ' has suggested some degree of hormonal

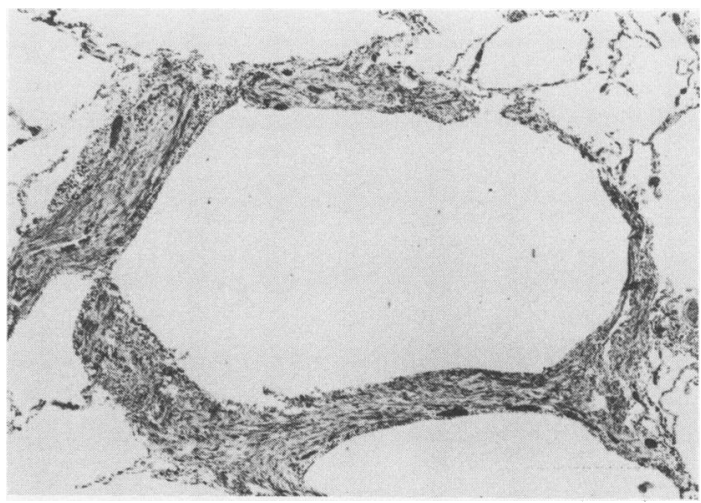

Fig 2 Higher magnification photomicrograph showing irregular bundles of smooth muscle fibres around a distorted small airway. (Masson's trichrome, $\times 38$.) 
influence. Further evidence for hormonal effects in lymphangioleiomyomatosis has recently emerged, with the documentation of steroid, oestrogen, and progesterone receptors in lung biopsy material. ${ }^{3}$ Treatment by oophorectomy $y^{4}$ or with progesterone ${ }^{5}$ even in receptor negative cases $^{6}$ has resulted in clinical improvement.

Our patient is unusual in several respects: her advanced age on presentation, a previous history of hysterectomy with oophorectomy, and a prolonged course of disease. In a search of published reports we could find only four patients who were older than 55 when they developed symptoms. ${ }^{78}$ Three of these patients were alive at the time of review, surviving two, nine, and 19 years; while the fourth had died eight years after presentation. Two lung biopsies had been performed on the long term survivor? with an interval of 10 years and histological examination had shown only mild progression of muscular proliferation.

Our patient had developed symptoms at the age of 60 , five years after oophorectomy. We suggest that the slow progression of her disease reflects both its initiation in the perimenopausal period and the reduction of steroid dependent muscle proliferation by oophorectomy. Muscular proliferation in the lung in our patient was milder than in most cases.

Lymphangioleiomyomatosis has characteristic radiological, pulmonary physiological, and pathological patterns. ${ }^{\text {I }}$ Inapparent hormonal influences may obscure the clinical findings and delay diagnosis. We believe that the pro- longed course in this elderly postmenopausal woman provides further evidence for the role of oestrogenic steroids in this condition.

\section{References}

1 Carrington CB, Cugell DW, Gaensler EA, et al. Lymphangioleiomyomatosis. Am Rev Respir Dis 1977;116:977-96.

2 Gray SR, Carrington CB, Corong JL. Lymphangiomyomatosis: report of a case with urethral involvement and chyluria. Cancer $1975 ; 35: 490-8$.

3 Brentani MM, Carvalho RR, Saldiva PH, Pacheco MM, Oshima CTF. Steroid receptors in pulmonary lymphangiomyomatosis. Chest 1984;85:96-9.

4 Banner AS, Carrington CB, Emory WB, et al. Efficacy of oophorectomy in lymphangioleiomyomatosis and benign metastasizing leiomyoma. $N$ Engl J Med 1981;305:204-9.

5 McCarty KS, Mossler JA, McLelland R, Sieker HO. Pulmonary lymphangiomyomatosis responsive to progesterone. $N$ Engl J Med 1980;303:1461-5.

6 Dishner W, Cordasco EM, Blackburn J, Demeter S, Levin H, Carey WD. Pulmonary lymphangiomyomatosis. Chest 1984;85:796-9.

7 Bradley SL, Dines DE, Soule EH, Muhm JR. Pulmonary lymphangiomyomatosis. Lung 1980;158:69-80.

8 Silverstein EF, Ellis K, Wolff M, Jaretzki A. Pulmonary lymphangiomyomatosis. Am J Roentgenol 1974;120:832-50.

9 Corrin B, Liebow AA, Friedman PJ. Pulmonary lymphangiomyomatosis. Am J Pathol 1975;79:347-82. 